\title{
WAYANG SEBAGAI SUMBER INSPIRASI DAN ENERGI DALAM SASTRA INDONESIA MODERN: ANALISIS GENETIS RESEPTIF
}

\section{Edy Sutanto}

Fakultas Bahasa dan Sastra, Universitas Nasional Jakarta edysutanto82@yahoo.com

\begin{abstract}
ABSTRAK
Wayang diperkirakan muncul pada 34 abad yang lalu diduga sebagai prototipe gerne literatur sastra Indonesia modern yang muncul pada hampir satu abad yang lalu. Sebagai bagian yang tak terpisahkan dari masyarakat modern, di samping sebagai imaginasi dan kreativitas, sastra juga membawa fungsi sosial. Pada masa-masa tertentu sastra juga dapat difungsikan sebagai konservasi semangat nasional, hukum, ekonomi, konvensi, etika, dan sistem sosial lainnya. Sastra Indonesia modern ketika dilihat melalui elemen penokohan secara konseptual merupakan kombinasi antara modernisasi dan tradisi. Bentuk, isi, dan struktur naratifnya dipengaruhi oleh sastra Barat, konvensi novelistik. sedangkan energi struktur arketipalnya diambil dari Timur, melalui dunia wayang.
\end{abstract}

Kata kunci: novel, wayang, estetika, arketipe, sastra, tradisi.

\begin{abstract}
ABSTACT
Wayang was born almost 34 century ago and modern Indonesian literatur was born almost a century ago. As integral part of modern society as well as an imagiation and creativity, literature also carries a social funtion. At certain periods literature can also be functioned as conservation of national enthusiasm, law,economic, convention, ethics, and other social systems. Modern Indonesian Literature, especially when it is viewed through its caracterization element is conceptually a combination between modernization and tradition. Its form, content, and narative structure were influenced by Western literary tradition, novelistic convention. Where as its energy its archetypal structure, were taken from east, thrugh wayang world.
\end{abstract}

Keywords: novel, wayang, esthetics, archetype, literature, tradition. 


\section{PENDAHULUAN}

Wayang adalah salah satu unsur kebudayaan Indonesia yang mengandung nilai seni, pendidikan dan nilai pengetahuan yang tinggi yang menjadi sumber inspirasi dan energi bagi pengarang-pengarang sastra Indonesia modern untuk menciptakan karya sastra. Ir. Sri Mulyono dalam bukunya Wayang Asal-usul, Filsafat dan Masa Depannya menyebutkan bahwa pertunjukan wayang kulit dalam bentuk yang asli dalam peralatan yang sederhana dipastikan berasal dari Indonesia dan diciptakan oleh bangsa Indonesia di Jawa, dan timbulnya sebelum kebudayaan Hindu datang. Yakni kira-kira pada tahun 1500 Sebelum Masehi, berumur lebih dari 3400 tahun (Mulyono: 1978: 1 - 2). Begitu halnya dengan sastra Indonesia modern Prof. Dr. Rachmad Djoko Pradopo dalam buku Beberapa Teori Sastra, Metode Kritik, Dan Penerapannya, mengatakan bahwa kesusastraan Indonesia modern merupakan respon atau tanggapan dari keusastraan Indonesia lama yang meupakan kesusastraan daerah-daerah atau satra Nusantara. (Pradopo, 2008: 1 -7).

Pada umumnya para sarjana sastra sependapat bahwa sastra Indonesia modern lahir awal abad ke-20, diawali dengan terbitnya Azab dan Sengsara (Merari Siregar, 1920) dan kumpulan puisi Tanah Air (Muhammad Yamin, 19922). Usia yang masih relatif muda tersebut memungkinkan timbulnya berbagai masalah , baik yang berkaitan dengan kualitas, dalam hal ini meliputi isi dan bentuk, maupun kuantitas dalam hal ini jumlah penerbitan dan mekanisme penyebarluasannya. Sesuia dengan judulnya, dengan memanfaatkan teori strukturalsme genetik (Goldman, 1981: 35 - 53) dan resepsi pembaca (Jauss, 1983: 3 - 45), tulisan ini mencoba menampilkan salah satu aspeknya, yait rekonstruksi karakterisasi sepanjang sejarahnya yang secara genesis reseptif diasumsikan berasal dari tradisi wayang. Dikaitkan dengan unsur penokohan tersebut, maka analisis berikut akan dipusatkan pada jenis novel.

\section{SASTRA INDONESIA MODERN}

\subsection{Kualitas Pragmatis}

Sastra Indonesia modern adalah karya yang ditulis dengan menggunakan bahasa Indonesia. Sesuai denga kondisi-kondisi yang melatarbelakanginya, baik dalama kaitannya dengan pengarang sebagai produsen maupun pembaca sebagai kunsumen, maka bentuk dan lainnya mengacu pada ciri-ciri kehidupan masyarakat modern.

Dikaitkan dengan proses di atas, kelahiran yang terjadi secara simultan yaitu antara medium bahasa dengan gerakan-gerakan politik, dengan ciri intensitas semangat nasional di dalamnya, maka sesungguhnya sastra Indonesia, khususnya pada masa-masa kelahirannya, sarat dengan pesan (Kartodirdjo dkk, 1987: 144 - 147) . Koskuensi logis yang ditimbulkannya 
adalah kurangnya kualitas unsur-unsur lain, seperti plot dan penokohan, khususnya kualitas estetisnya, yang justru merupakan hakikatnya.

Keterlibatan indikator sastra di atas menimbulkan implikasi yang lebih luas yaitu sempitnya pemahaman terhadap masalah-masalah sosial di sutu pihak, dan kuarngnya intensitas proses kreatif di pihak yang lain. Seperti diketahui sejak Balai Pustaka hingga sekarang dengan mempertimbangkan relevansi periodisasinya masing-masing, sudah dihasilkan karya sastra yang bermutu. di antaranya: Siti Nurbaya, Belenggu, Atheis, Bumi Manusia, Para Priyayi, Layar Terkembang, Rindu Dendam, Tidak Ada Esok, Atheis,Hati yang Damai, Pelabuhan Hati,Saman, dal lain-lain.

\subsection{Kualitas Estetis}

Ciri khas, hakikat, dan daya tarik sastra terletak dalam kualitas estetisnya. Benar karya sastra mesti mempertimbangkan keseimbangan antara hakikat dengan manfaat, bentuk dengan isi, tetapi tujuan akhir sastra adalah unsur yang pertama. Artinya, dalam karya sastra, eksploitasi terhadap medium bahasa adalah prioritas, posisisnya mendominasi tujuan-tujuan tertentu yang mesti dicapai. Meskipun demikian, sastra tanpa mengandung tujuan tertentu, seni untuk seni, misalnya juga dianggap tidak relevan.

Dengan mempertimbangkan keterkaitan antara bentuk dengan isi, maka kualitas estetis dihasilkan melalui kedua aspek tersebut, yaitu melalui medium bahasa dan pesan. Estetika bahasa dihasilkan melalui stilistika, sedangkan estika pesan dihasilkan melalui cerita dan penceritaan (plot). Sebagai akibat, sesuai dengan visi kontemporer, baik estetika bahasa dengan estetika pesan lahir dengan adanya pertemuan dengan pembacanya, sebagai konstruksi resepsi. Teeuw (2013: 157 - 177) mengitroduksi kualitas estetis karya dalam bentuk tegangan-tegangan.

Kompleksitas sastra modern jelas merupakan representasi kompleksitas kehidupan masyarakat modern. Artinya, dalam rangka menampilak aspek-aspek estetisnya, sastra Indonesia modern memanfaatkan berbagai sarana yang diperoleh melalui sistem komunikasi modern. Meskipun demikian,sebagai bagian masyarakat agraristradisional di suatu pihak, sebagai representasi gudng memori masa lampau di pihak yang lain, sastra Indonesia mengadopsi secara intens pola-pola naratif tradisi. Wayang diduga sebagai prototipe genre literer sastra Indonesia modern.

\section{WAYANG DAN SASTRA INDONESIA MODERN}

\subsection{Persamaan}

Novel dan wayang merupakan dua jenis karya seni yang memiliki sejumlah persamaan dan perbedaan, baik yang berkaitan dengan subjek pelaku, yaitu pengarang dan dalang, maupun karya seni sebagai totalitas, yaitu pembacaan dan pementasan. Pengarang sebagai kreator dan dalang 
sebagai narator, kedunya adalah subjek kreatif yang merupakan fokus pertama aspek estetis. Artinya, kedua jenis karya seni dianggap sebagai karya yang estetis apabila di dalamnya, baik kreator maupun narator berhasil untuk menampilkan rangkaian kejadian dan karakterisasi tokoh-tokohnya, citra masyarakat dengan interaksi para pendukungnya sekaligus memplotkannya secara logis, sehingga dipahami oleh audiensi masing-masing. Secara sosiologis genetis, sebagai anggota masyarakat, keduanya juga memiliki misi yang sama, yaitu menampilkan karya-karya yang disesuaikan dengan kompetensi masyarakat yang melatarbelakanginya.

Sebagi karya seni, wayang dan novel merupakan totalitas. Dengan medium bahasa lisan, wayang adalah totalitas yang didukung oleh komunitas audiensi, kualitasnya adalah proses pementasan. Sebaliknya, dengan medium bahasa tulis, novel juga merupakan kesatuan yang cukup diri, didukung oleh pembaca, kualitasnya adalah proses pembacaan. Sebagai karya seni, wayang dan novel, seharusnya diresepsi sebagai idiologi yang nonideologis, seperti kenyaataan tetapi bukan kenyataan itu sendiri.

Hakikat imajinasi memiliki persamaan yang signifikan dengan bayangana sebagai unsur utama dalam pementasan wayang. Persamaan ini lebih jelas dalam wayang Bali, di mana penonton hanya menyaksikan bayangan tersebut, yang dipisahkan secara transparan dengan dalang melalui layar. Apabila esensi fiksi adalah imajinasi, bagaimana pembaca menangkap makna kehidupan dalam kaitannya dengan kenyataan yang sebenarnya, yang pada akhirnya menyajikan makna yang jauh lebih mendalam apabila dibandingkan dengan kejadian yang sesungguhnya, maka esensi wayang (Bali) adalah citra di balik layar, yang melaluinya aspek-aspek estetis lebih tampak baik melalui wacana dalang maupun penampilan bayangan itu sendiri. Artinya, aspek-aspek estetis lebih hidup karena dalang dan wayang tersembunyi secara fisik, di balik layar, seperti juga pengarang dan kenyataan-kenyataan yang tersembunyi secara imajiner, di balik bahasa. Bandingkan juga dengan fisi sastra kontemporer yang secara sengaja menganggap pengarang sudah mati, meskipun sesungguhnya masih hidup, sebagai konstruksi anominitas (Barhtes: 1977: 145).

Persamaan aspek-aspek sosiologis genetis wayang dan novel masih banyak, kususnya dengan kaitannya dengan ciri-ciri pragmatisnya. Wayang dan novel memiliki nilai-nilai politis dan ekonomis, keduanya dapat dimnfaatkan untuk tujuan-tujuan praktis. Emansipasi wanita, keluarga berencana, partai politik tertentu dan lembaga sosial masyarakat, memiliki inventasi yang cukup besar di dalamnya. Satu hal yang mesti dihindarkan adalah aspek-aspek negatifnya, seperti penah dilakukan oleh PKI/Lekra tahun 1960-an. 


\subsection{Persamaan}

Persamaan di atas bukan persamaan mutlak. Wayang dengan novel berbeda secara esensial, khususnya dalam kaitannya dengan medium. Medium novel adalah bahasa tulis, merupakan hasil teknologi modern, dipahami secara individual, sedangkan medium wayang adalah bahasa lisan dengan seperangkat instrumen, dipentaskan secara langsung dalam suatu komunitas. Dalam hubungannya dengan unsur penokohan, sesuai dengan judul pembicaraan ini, keduanya diduga mempunyai kaitan yang bersifat genetis evolusionis, seperti tampak dalam novel-novel Indonesia modern pada umumnya.

Perbedaan pokok, khususnya dalam kaitannya dengan subjek dapat dijelaskan seperti berikut ini. Acuan pengarang adalah struktur sossiokultural, sedangkan acuan dalang adalah cerita tertentu, khususnya Mahabharata dan Ramayana. Dalam sastra, aktivitas kreatif dan imajinasi mengalir lebih bebas, intensitas pemahaman terhadap masalah-masalah kehidupan lebih mendalam, suatu hal yang tidak mungkin dalam pementasan wayang yang dilakukan secara langsung. Pada tarap tertentu, tulisan novel, seperti novel sejarah dan novel ilmu pengetahuan, tidak berbeda dengan penulisan karya ilmiah, bahkan diawali dengan suatu penelitian. Sebagai pementasan langsung, wayang memerlukan formula-formula, unsur-unsur yang dinafikan dalam aktivitas kreatif sastra. Dalam wayang aspek hiburan lebih menonjol, karena itulah dagelan memegang peranan penting, bersifat eksplisit. Heterogenitas penikmat, seperti usia, latar belakang sosial dan intelektualitas lebih tinggi.

Dalam pementasan wayang dimungkinkan terjadinya hubungan fisik antara subjek dengan audiensi, bahkan juga dengan seluruh komponen yang mendukungnya, seperti patron, sponsor, dan kritikus. Dengan adanya kaitan secara fisikal, maka suara, nada, sosok tubuh subjek, dan berbagai ornamentasi yang menyertainya ikut menentukan kualitas pementasan, sekaligus pemasarannya. Dalam novel, masalah yang terakhir ini secara keseluruhan telah digantikan oleh institusi lain, penerbit.

Novel diresepsi secara individual, dapat dilakukan berulang-ulang terhadap objek yang sama, sedangkan wayang diresepsi secara komunal, dibatasi oleh ruang dan waktu. Plot novel dipahami sementara dibaca, terikat oleh struktur narasi bahasa tulis, sedangkan plot wayang dipahami sementara dipentaskan, terikat oleh struktur naratif oleh bahasa lisan. Dalam hal ini wayang lebih dinamis sebab di satu pihak, dilakukan melalui komunikasi langsung antara pengirim dengan penerima. Di pihak lain, plot berubah dalam setiap pementasan meskipun dilakukan oleh subjek dan dengan cerita yang sama. Kelebihan novel adalah kemampuannya dalam mengevokasi kompetensi pembaca sebab dapat dipahami secara berulang-ulang, tidak terikat oleh ruang dan waktu. 


\section{TRADISI WAYANG DAN TRADISI SASTRA INDONESIA MODERN \\ 4.1. Strukture arketipe}

Kritik sastra pola dasar berpendapat bahwa arketipe menentukan bentuk dan fungsi dari karya sastra dan makna teks ini dibentuk oleh budaya dan psikologis mitos. (https://en.wikipedia.org/wiki/archetype). Struktur mitos atau struktur arketipe, khususnya yang dilacak melalui jalur psikologi analitik Yungian (1949: 377 - 380) sebagai ketaksadaran impersonal: yaitu filogenesis, menyarankan bahwa setiap aktivitas kreatif didasarkan atas kecenderungan tertentu, yang merupakan sebab-sebab pokok timbulnya karya seni, sebagai energi. Struktur arkrtipe tidak mesti bersifat eksplisit, tidak nyata, tetapi dirasakan adanya, sebagai ketaksadaran yang disadari. Hakikatnya suprarasial dan supraindividual, tetapi bukan berarti tidak rasional. Pada umumnya menjelma menjadi pandangan dunia. Struktur artikepe dianggap sebagai deposit ratusan, bahkan ribuan tahun seperti simponi bagi dunia musik, panorama sunset bagi seni lukis, cerita-cerita cowboy bagi penulisan novel detektif, mitologi Yunani bagi penulisan novel Eropa.

Sebagai muatan ketaksadaran, struktur arketipe bukan peniruan secara harfiah, tidak mesti dianggap sebagai gejala ynag statis, melainkan sebagai kalitas yang signifikan. Sebagai energi, kualitas arketipe justru dianggap menyediakan ciri-ciri psikisyang terorganisasikan, khusussnya dalam proses kreatif. Manifestasi pola-pola naratif dan tipologi karakterisasi dalam sastra Indonesia moder yang akan dibicarakan berikut ini, menunjukkan dengan jelas gejala tersebut.

Secara sosiologis, sastra tidak lahir dari kekosongan, tetapi melalui usul-usul dan tujuan tertentu, sebagai aspek historisitas, dan memiliki arti justru karena adanya tendensi-tendensi. Pikiran, khususnya imajinassi subjek, tidak pernah mengembara dalam ketakterbatasan, tidak arbitrer, juga bukan tabula rasa, tetapi sudah terikat sebelumnya, oleh kekuatan-kekuatan semacam gravitasi, bahkan sebagai cetak biru. Mahakarya pun sesungguhnya lahir melalui tendensi-tendensi tertentu, termasuk pola-pola arketipe (Goldman, 1978: 31 - 39).

\subsection{Struktur Karya Sastra}

Melalui medium bahasa, karya sastra, dalam hal ini novel, dibangun sebagai sebuah struktur. Pada gilirannya, karya sastra bukanlah arketipe itu sendiri, mitos hanya berfungsi sbagai fondasi-fondasistruktural (Frye, 1973: 52 - 53). Melalui kapasitas regulasi diri, karya sastar lahir sebagai kualitas yang sama sekali baru, entitas yang seolah-olah dilihat untuk pertama kali. unsur ang diamnfaatkan adalah mekanisme pemplotan. 
Sejajar denagn energi arketipe di atas, maka struktur karya sastra Indonesia modern, khususnya penokohan dan ceritanya, baik secara langsung atau pun tidak langsung, diadopsi melalui tradisi dan konvensi budaya di mana karya sastra tersebut dilahirkan. Salah satu yang dimanfaatkan oleh pengarangdalam menghasilkan karya sastra adalah dunia pewayangan (cf. Damono, 1993: 363 - 254; Kartidirdjo dkk., 1987: 146).Ciri-ciri arketipe pada gilirannyamemicu pola-pola naratif, mengorganisasikan secara struktural bentuk-bentuk literer, yang sekaligus menyediakan bagi subjek kreator suatu dunia metaforis total. Dalam proses kreatif, imajinasi memerlukan energi lain yang berfungsi sebagai indikator. Kemampuan imajinasi justru merupakan koeksistensi. Dengan mengadakan penyusunan kembali terhadap fakta-fakta kultural sebelumnya, khususnya terhadap unsur cerita dan penokohan.

\section{PENOKOHAN SASTRA INDONESIA MODERN.}

\subsection{Struktur Penokohan}

Penokohaan sangat menonjol dalam karya seni yang memanfaatkan struktur naratif, baik karya seni yang emanfaatkan medium tulisan maupun lisan, seperti: cerpen, novel, drama, epos, dongeng dan wayang. Kecenderungan ini dapat dijelaskan melalui peranan indikator psikis, identik dengan sifat-sifat penikmat, berikut. (a) Secara fisik penokohan paling mudah dikenali, khususnya melalui identifikasi nama. (b) Secara psikis, identik dengan sifat-sifat penikmat, khususnya apabila dikaitkan dengan kehidupan nyata sehari-hari. (c) Secara konseptual paling mudah untuk dipahami, khususnya dalam kaitannya dengan kejadian. (d) Sepanjang sejarah kemanusiaan, khususnya pada abad Romantik, subjek selalu menjadi pusat perhatian. (e) Meskipun dengan cara yang berbeda, visi kontemporer memberikan hak istimewa terhadap eksistensi subjek sebagai subjek tranindividual.

Sebagai ego manusia pada dasarnya tidak lengkap. Karenai itulah, ia mesti mengenali diri sendiri melalui tokoh-tokoh fiksional, yaitu pengalaman dialektis antara rekaan dengan kenyataan. Tokoh-tokoh fiksional tidak pernah mati, meskipun dalam cerita sesungguhnya sudah mati sebab secara terus menerus dihidupkan kemabali oleh pembaca berikutnya. Justru pengaranglah yang dianggap sudah mati, meskipu sesunguhnya masih hidup, sebagai anominitas.

Penokohan merupakan salah satu unsur karya, di samping kejadian, plot, latar, dan tema. Penokohan menyajikan bagaimana para pelaku dalam suatu cerita. Penokohan melalui kompentensi medium bahasa figuratif konotatif berfungsi untuk menampilkan esensi tokoh-tokoh, interdependensinya dengan perilaku manusia dengan kenyataan sehari-hari, sebagai karakterologi, sekaligus acuannya dengan manusia pada umumnya 
sebagai hakikat universal. Di satu pihak, penokohan memiliki konteks dialektis dengan peristiwa. Di pihak yang lain, penokohan dan peristiwa memiliki konteks logis dengan plot. Artinya, keseluruhan pesan pengarang terkandung dalam dua unsur pertama, tetapi dapat dimengerti semata-mata hanya setelah memahami unsur terakhir.

\subsection{Peranan Pengarang}

Peranan pengarang dalam hubungan ini diperimbangksn sekaligus sebagai individu dan transindividu, ontogenesis dan filogenesis dalam kaitannya dengan otoritas tradisi. Sebagai individu pengarang berfungsi untuk menampilkan kekayaan intelektual dan emosional yang diperoleh sejak masa kaanak-kanak hingga dewasa, khususnya pada masa-masa suburnya proses kreativitas, sebaliknya sebagai transindividu pengarang merepresentasikan kekayaan tradisi, sebagai akumulasi impersonal, yang diperolh melalui deposit nenek moyang.

Sebagai subjek kreator, sejak zaman Plato/Aristoteleshingga pascastrukturalisme peranan pengarang mengalami fluktuasi yang cukup beragam. Sarana-sarana yang dimanfaatkan untuk memanipulasikannya, diaantaranya: anonimitas dan pengarang jamak (pascastrukturalisme), sudut pandang (struturalisme), relevansi subjek (Abad Romantik), dominasi sistem religi (Abad Pertengahan), mimesis (Zaman Plato/Aristoteles). Hanya pada abad Romantik (Abad ke-19) pengearang menduduki posisi yang menentukan. Tujuan terakhir yang hendak dicapai jelas untuk memberikan perhatian yang lebih besar terhadap peranan karya yang dihasilkan, bukan pengarangnya.

Melalui sistem simbul bahasa, tujuan pengarang adalah menyampaikan pesan. Dengan kalimat lain, keseluruhan karya tersebut sesungguhnya adalah pesan (Langer, 1953: 31 - 32). Sebagai pesan, sifatnya tidak memaksa, tidak mengandung sanksi. Sama dengan karya sastra, tradisi itu sendiri pada dasarnya merupakan pesan. Hanya sebaian kecil tradisi yang bersifat mengikat, sebagai hukum-hukum imperatif, yaitu masalah-masalah yang berkaitan dengan peraturan, norma, tabu, dan larangan. Atas dasar pemahaman tersebutlah dianggap tepat apabila karya sastra, karya seni pada umumnya secara terus-menerus memanfaat kekayaan traddisi sebagai sumber kreativitas.

\subsection{Peranan Tradisi}

Pemahaman mengenai kesejarahan umat manusia menunjukkan bahwa sebagian besar energi, semangat, kegairahan, dan cita-citanya ditentukan melalui masaa lampau, baik sebagai manifestasi ontogenesis (individual) maupun filogenesis (komunal). Meskipun demikian, sebagai energi proses kreatif, ciri-ciri yang terakhirlah yang lebih berperanan. Siklus 
kehidupan manusia secara individual, sejak masa kanak-kanak hingga dewasa, dianggap terlalu singkat untuk mengadopsi keberagaman kekayaan trdisi. Dalam hubungan inilah inddividu memerlukan siklus antargenerasi, penyebaran aspek-aspek ssosiokultural melalui peranan subjek transindividual, peranan spesies dan rasial yang tidak dibatasi oleh ruang dan waktu.

Salah satu tradisi adalah wayang itu sendiri. Dunia pewayangan dianggap sebagai nasal-usul, prototipe, sekaligus model penokohan sastra Indonesia modern. Dugaan tersebut didasarkan aatas kenyataan bahwa wayang merupakan: (a) Gudang bahasa sesuai dengan kemampuan narator untuk mengekspresikannya. (b) Gudang cerita dengan berbagai tema, episode dan carangannya. (c) Gudang tokohdengan berbagai tipe dan karakterisasinya. (d) Gudang aspek etika dan estetika dengan keberagaman bentuk sesuai dengan pesan-pesan yang disampaikannya. (e) Gudang filsafat hidup sesuai dengan permasalahan dan pemecahannya. (f) Gudan memori masa lampau yang sudah diinvestasikan sejak ratusan bahkan ribuan tahun.

Sebagai sastra lisan, wayang merupakan sistem simbul yang memberikan kemungkinan luas bagi aktivitas kreatif lainnya, khususnya sastra. Dugaan ini didasarkan atas kenyataan berikut. Pertama, secara genesiswayang diciptakan sebagai tiruan kehidupan manusia yang ssungguhnya. Wayang merupakan salah satu cara yang mudah untuk meniru bentuk-bentuk fisik manusia, sekaligus memanipulasikannya ke dalam bentuk-bentuk lain yang secara anatomis psikologis $d$ apat mewakili sifatsifatnya. Misalnya, Bima untuk orang yang kuat, Arjuna untuk orang yang lemah-lembut, Raksasa untuk orang loba, dan sebagainya. Kedua, sesuai dengan hakikat manusia, sebagai permainan, wayang merupakan media untuk mendidik sekaligus mengkritik, meskipun secara tidak langsung. Tokohtokoh adalah alat, yang mlaluinya disifatkan mengenai kehidupan manusia sehari-hari. Ketiga, sebagai model, wayang merupakan komunitas fiksional, yang melaluinya masyarakat meneladani. Pada taraf tertentu, bentuk-bentuk fiksional sejajar dengan sistem religi, khususnya dalam rangka menularkan kode-kode etik.

Sebagai mitos, dalam proses kreatif, dalam banyak hal seperti tradisi di atas menyediakan bahan-bahan, kerangka acuan, memori, yang siap dipakai, sebagai prototipe. Dalam hal ini, dapat disebutkan jawanisasi karyakarya Ahmad Tohari, Umar Kayam, Danarto, Linus Suryadi, dan Mangunwijaya. Ciri-ciri arkhais karya-karya Chairil Anwar, Sutarji, Rendra, dan Dnarto juga memiliki kecenderungan tersebut. Contoh yang jelas, ceritacerita wayang dimanfaatkan sebagai tulang punggung karya, misalnya Arjuna Mencari Cinta karangan Yudhistita.

Sesuai dengan judul tulisan ini, kualitas arketipe siknifikan yang diadopsi oleh sastra Indonesia modern adalah unsur penokohannya. Hal ini 
tampak misalnya dalam novel-novel Balai Pustaka, dengan pemisahan secara jelas antara tokoh datar dengan tokoh bulat, kelas menengah atas dengan kelas menengah bawah, tokoh jahat dengan tokoh jujur. Apabila dalam wayang eksistensi tokoh dapat disaksikan secara nyata, secara visual, antara tokoh yang kuat dan lemah, maka dalam novel yang dimanfatkan adalah deskripsi lewat narasi. Dalam hubungan dapat disebutkan misalnya bentukbentuk fisik Datuk Maringgih dalam Siti Nurbaya, Tuti dan Maria dalam Layar Terkembang dan sebagainya.

Etika, estetika, dan filsafat hidup pada umumnya, jelas terkandung dalam dunia pewayangan, seperti yang terkandung dalam epos Mahabharata dan Ramayana. Sebagai bagian integral kebudayaan India, bagi pengarang nama kedua epos tersebut dianggap sebagai mitos, model, sekaligus energi proses kreatif. Wayang merupakan sumber pendidikan dan pengajaran, ditularkan dalam kehidupan praktis sehari-hari, khususnya dalam karya sastra, seperti mahakarya, pada gilirannya identik dengan filsafat, dengan ilmu pengetahuan, pengarang identik dengan filsuf, dengan ilmuwan.

Tradisi wayang bukanlah satu-satunya mitos yang menggarisbawahi aktivita skreatif satra Indonesia modern. Para sarjana sependapat bahwa Otoritas tradisi yang ada di Nusantara ini secara bersama-sama memiliki investasi yang besar terhadap perkembngan sistem estetis. Keberagaman dan kekayaan seni gerak, seni patung, seni bangunan, seni lukis, dan eni suara menunjukkan dengan jelas bahwa tradisi memegang peranan yang sangat penting.

Ottoritas tradisi seperti di atas secara imperatif mengarahkan subjek kreator untuk mencipta yang disesuaikan dengan kompetensi masyarakat. Sama seperti dalang yang dibayangi oleh sistem estetis yang berada dalam teks, alm mencipta, pengarang juga secara terus menerus dibayangi oleh sistem sosiokultural, yaitu mitos itu sendiri. Kebebasan pengarang adalah kebebasan yang sudah dikerangkakan oleh sistem kultural, sebagi kebenaran semu (cf. Kuntowijoyo, 1984: 127 - 136).

Pengarang adalah subjek yang terikat oleh hakikat indiviidu sekaligus sosial, subjek dengan kebebasan kreatif sekaligus konservasi normatif. Periode Balai Pustaka mesti memelihara dan mempertahankan norma-norma pemerintah Kolonial Blanda. Pujangga Baru nasionalisme, Angkatan 45 revolusi kemerdekanan, periode sesudahnya sampai sekarang sibuk dengan pertanyaan sekitar identitas bangsa di tengah-tengah globalisasi. Sastra akhirnya tidak berbeda dengan sistem ekonomi, politik, dan sistem sosial pada umumnya.

Adopsi ciri-ciri karakterisasi sastra Indonesia modern melalui dunia pewayangan bukan berarti stagnasi, degradasi, bukan involusi sastra. Ciri-ciri arketipe bukan dalam pergantian negatif, tetapi justru sebagai energi, sebagai kualitas tranformatif yang memungkinkan bagi subjek kreator untuk 
mengadaptasikan energi imajinasinya ke dalam struktur fiksional. Peneeeiruan dalam proses mencipta justru harus diarahkan pada kreativitas seperti Faust karya Goethe yang diambil melaui cerita rakyat Jerman. Tjokot seniman patung Bali yang menciptakan patung-patungnya atas dasar struktur urat dan serat kayu. Masalah yang dikemukakan dalam kesempatan ini , seperti disebutkaan di atas adalah kualitas evolusionis, adopsi sistem estetis sastra Indonesia modern melalui tradisi wayang, seperti ditunjukkan melalui manifestasi karakterisasi struktur naratif, dan mekanisme pemecahannya.

\section{SIMPULAN}

Wayang sebagai salah satu unsur kebudayaan Indonesia yang mengandung nilai-nilai seni, pendidikan, dan nilai-nilai pengetahuan yang tinggi diperkirakan muncul kira-kira pada 34 abad yang lalu. Sedangkan Sastra Indonesia modern lahir hampir satu abad yang lalu. Sebagai bagian yang tak terpisahkan dengan masyarakat modern, di samping sebagai imajinasi dan kreativitas, sastra juga mengemban fungsi sosial. Sastra difungsikan sebagai konservasi semangat nasional, hukum, ekonomi, adat istiadat, etika, dan sistem sosial lainnya.

Sastra Indonesia modern, khususnya apabila dilihat melalui unsur penokohannya, secara konseptual merupakan perpaduan antara modernisasi dan tradisi. Bentuk, isi dan struktur naratifnya dipengaruhi oleh tradisi literer Barat, tradisi novelistik, sedangkan energinya, struktur arketipalnya diambil dari Timur, melalui sistem religi, adat istiadat dan kebiasaan, tradisi dan konvensi, norma dan etika, khususnya dunia pewayangan.

\section{DAFTAR PUSTAKA}

Barthes, Roland, 1977. Image, Music, Text. New York: Hillard Wang.

Damono, Spardi Djoko, 1993. Novel Jawa Tahun 1950-an, Telaah Fungsi, Isi, dan Struktur. Jakarta: Pusat Pembinaan dan Pengembangan Bahasa.

Frye, Northrop, 1973. Anatomy of Criticism: Four Essays. New Jersey: Princeton University Press.

Goldmann, Lucien, 1976. Cultural Creation In Modern Society. Saint LouisLouis: Telos Press. 
, 1981. Method in The Sociology of Literature. Oxford: Basil Blackwell Publisher.

Jauss, Hane Robert, 1983. Toword an Aesthetic of Reseption. Minneapolis: University of Minneasota Press.

Jung, C.G., 1949. Psychological Type orthe Psichology of Idividuation. London: Routledge \& Kegan Paul, Ltd.

Jungian archetypes - Mammy Bad Boy - Archetypal Literary Criticism. dalam https://en.wikipedia.arg/wiki/archetype (diunduh tanggal 2 Agustus 2016).

Kartodirdjo dkk., 1987. Perkembangan Peradapan Priayi. Yogyakarta: Gajah Mada University Press.

Kuntowijoyo, 1987. Budaya dan Masyarakat. Yogyakarta: Tiara Wacana.

Langer, Susanne K., 1953. Feeling and Form a Theory of Art. New York: Charles Scribner's Sons.

Mulyono, Sri, 1978. Wayang Asal-usul, Filsafat dan Masa Depannya. Jakarta: Gunung Agung.

Pradopo, Rachmat Djoko, 2008. Beberapa Teori Sastra, Metode kritik, Dan Penerapannya.Yugyakarta: Pustaka Pelajar.

Teeuw, A., 2013. Sastra dan Ilmu Sastra: Pengantar Teori Sastra. Jakarta: Pustaka Jaya. 